\title{
AN INVESTIGATION OF THE RELATIONSHIP BETWEEN THE MOTHER TONGUE WITH COLLECTIVISM AND SOCIAL COOPERATION AMONG ILAMIAN FEMALE STUDENTS IN ILAM UNIVERSITIES
}

\author{
Ferdows Hashemi ${ }^{1}$, Qasem Seydi ${ }^{2}$
}

M.A degree, Dept. of Linguistics, Ilam University, Ilam, Iran

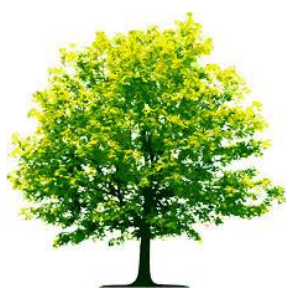

Keywords: Mother tongue, Ilamian students, collectivism, cooperation.

\begin{abstract}
A B S T R A C T
Mother tongue has an undeniable effect on forming personality and identity of the child. Since, our country is a developing one, and one of the main ways to program in order to reach the development is the attention to cooperation and participation in society individuals. So, the present work is to investigate the relationship between mother tongue with collectivism and social cooperation in Ilamian female students in Ilam universities. This is a field investigation, and its instrument is a questionnaire. Both collectivism and cooperation questionnaires do have validity; and Cronbach Alfa for all variables has been up to 0/7. The research community consists Ilamian female students in universities of Ilam city. Research sample consists 600 individuals extracted using clustering method. Findings showed that mother tongue has a meaningful and positive relationship with collectivism and cooperation. Daughters who speak their mother tongue had tendency much more toward collectivism and cooperation in comparison to the ones whose first language wasn't their mother tongue. Also, findings showed that there is a correlation between dependent variables of the research, collectivism and cooperation; that is, the more tendency toward collectivism the more cooperation.
\end{abstract}

Citation: Ferdows Hashemi, Qasem Seydi (2018). An Investigation Of The Relationship Between The Mother Tongue With Collectivism And Social Cooperation Among Ilamian Female Students In Ilam Universities. International Journal of Advanced Multidisciplinary Scientific Research (IJAMSR ) ISSN:2581-4281 Vol 1, Issue 6, August, 2018, \#Art.614, pp 35-43
Introduction

Mother tongue has been studied from different aspects and perspectives, and so different definitions has been represented in it. One rational and scientific definition seems to be the definition of the mother tongue based on synchronic and diachronic (historical) view. From synchronic point of view, the first language or the mother tongue is defined as a language or languages 


\section{International Journal of Advanced Multidisciplinary Scientific Research (IJAMSR) ISSN:2581-4281}

acquired by the child from his/her parents at home; and in fact, that is the vernacular and original language belonged to his/her parents. In definition of the mother tongue, some conditions are attended as the following ones: a language or languages that individual: a) have been exposed to them from the birthday and so will acquire them; b) he/she can speak them naturally, automatic and easily; c) he/she knows him/herself through those languages or others know him/her through those languages; d) he/she is very powerful in making communication by them without any difficulty; e) he/she has no accent when speaks them. But, in diachronic view, mother tongue, is not merely the language belonged to the child's mother. The term "mother" in "mother tongue" means "basic and original", such as mother university, motherland, mother industries, and etc.... accordingly, it can be said that mother tongue of everyone is his/her ancestors even if he/she can't speak it now.

Individualism and collectivism are two terms referring to the relationships between the individual and a small group like family or large group like society. In cultures which have a tendency toward individualism, competition is more encouraged than cooperation; personal purposes are preferred to the group purposes; individuals don't like to be dependent emotionally to organizations and social groups. In collectivist societies, people born in widespread families and groups, and so they are protected as the result of their faithfulness; individuals are depended emotionally on organizations and the social groups, and culture emphasizes on this dependence. Wenying (2001) introduced collectivism briefly as "to take personal purposes as secondary in favor of the group purposes", and individualism as "give priority to the personal purposes". This is a known fact that human being is a social animal, but degree of being social varies among different cultures. So individualism and collectivism are not the same in every society. This relation can be seen through families' formation. In some cultures, families are narrow (husband, wife, and child), and other families are expanded (grandfather, grandmother, aunt, uncle, cousin, niece). But also, there are people who live in thrives based on relationship. These varied structures affect human being through values and behaviors. In families which are quiet collective, individual, for instance, can feel himself/herself as faulty, even if no one is aware of his/her fault. However, in less complex societies, the individual may feel shame only when be aware of his/her fault. This show clearly the way that families affect human being views.

Social cooperation contains different kinds of individual and collective actions in order to interfere in determining one's fate and society fate, and affecting decision making processes about public issues. Cooperation can be proposed in mental, objective and cooperation, moral dimensions: the mental dimension of cooperation is a tendency to social cooperation created in the individual as the result of truth and other similar factors. Objective and behavioral dimension, which is revealed in the form of membership, supervision, fulfillment and decision making, is the same as individuals' objective connection; and the cooperation morality is defined as willing of all individuals to be involved in cooperation. Specific sense of the cooperative moral is the tendency and involvement of individuals in participating in inner activities and programs of the organization (Bloordi, 2012: 6). Cooperative moral is measured in the form of expressions about cooperation in over program scholarly 


\section{International Journal of Advanced Multidisciplinary Scientific Research (IJAMSR) ISSN:2581-4281}

activities, membership in scholarly groups, having the collective work moral and ethical... according to Allen Biro (2001), from a sociological perspective, we should distinguish cooperation as action and commitment (cooperation action) from cooperation as a state (cooperation case). In the first sense, cooperation refers to having an active participation in the group, and it is related to the social activity which has been done; and in the second sense, it refers to membership in a special group (Biro, 2001: 275). In another definition, cooperation has been defined as an informative process of the power division and rare resources, and it is to provide opportunity for the lower classes in order to improve their life conditions. Thus, when we consider cooperation as the process of reinforcing the people, it will be based on three values: "give people share in power and option, involve people in order to supervise in their fate, and open the development ways for low class individuals (Toosi, 1991: 8). And finally, Gaotry definition is: a social, public, integrate, comprehensive, multidimensional, and a multi culture process whose aim is to draw all people to play a role in all stages of the development (Gaotry, 2000: 36).

\section{Research significance}

According to the changes in nowadays society, the importance of crisis created in the individual and social level is a vital issue; because, according to Reuters (1995), this is action and structure causes the social fulfillment, and these are not apart from each other; and individuals' action forms construction, and the construction forms the action (Riterz, 1995: 701). Since, the individual is the base and foundation of each society, how can an actor produce an appropriate construction, and an individual's role is important in the process of development, his/her social position and also challenges created in the way of his/her social position seems to be significant to investigate. Without taking attention to the emotional dependency of the individual in society, programs and social policies won't have any protection, because programs, fulfillment and their applicability entail person's motivation in social life continuity and correlation with society. If, every one emphasizes on himself/herself, compatibility, correlation, and social unity will destroy, and individuals will not strive to maintain the social organizations. They will no more think to preserve the cultural and social possession and values. Such a state will lead to agitation and social disturbance. Clearly, such a society will not have the condition of development (Nateghpoor, 2004); also, in the importance of this research, we can say that daughters (future mothers) form the main foundation of family, and they affect directly on family and children training. So, the investigation of these damages and their eradication is a significant and vital issue.

Present research that investigates the relationship of mother tongue with collectivism and social cooperation, is to find answers to the following questions:

- Is there a meaningful relation between mother tongue and collectivism?

- Is there a meaningful relation between mother tongue and social cooperation?

- Is there a relation between collectivism and social cooperation? 


\section{International Journal of Advanced Multidisciplinary Scientific Research (IJAMSR) ISSN:2581-4281}

\section{Research Literature}

Ali (2006), in his research, investigated language, nationality and the collectivism relationship with application of the Farsi language in institutional environments in a region with the Turkish language. Research community consists of all male and female students, educating in Morgan region, in both urban and rural places in 2003-2004 educational year. His research showed that community of the region students is mainly a collectivist community; and this characteristic is one barrier against application of the Farsi language. On the other hand, interest in nationality and mother tongue is one of the characteristics of this region's students. Unlikely, but this characteristic has a positive relationship with the application of Farsi language as the second language.

Darbandi (2006), in "an investigation of collectivist behavior and view in Tehranian citizens", tried to identify variables affecting on collectivism or cooperation in the social sidetrack. The theoretical framework of his research is the rational option theory, whose analysis of human being's behavior, in addition to accounting, financial advantages and disadvantages, he signified attention to others' right and fairly behavior. Based on the research hypothesis, variables of public commitment, self-control, faithfulness, tendency to cooperate, belief in disadvantages of having no cooperation, truth in others' cooperation, satisfaction from life are effective on collectivism. The collectivist behavior investigated in his research is wayfarers' pause in front of the red light. The research sample consists 300 individuals who were to cross the red light from three crowded intersections in south, center, and north of Tehran. Based on the analysis of the research findings, except satisfaction of the life, relationship of all the variables with the dependent variable were confirmed.

And finally, some resolutions were suggested to increase cooperation in the social sidetracks: 1 . Reinforcement of others' right and collective commitment; 2. Training about the disadvantages of having no cooperation and advantages of cooperation; 3 . To create low costs for cooperation and high costs of having no cooperation; 4 . Reinforcement of the formal and informal supervision.

Yazdanpanah (2007), in his statistical research, investigated the degree, dimensions, and depth of the social cooperation and its barriers. The statistical sample was 880 individuals up to 18 years old in Tehran selected in a systematic accidental method. Based on the research findings, the more having no authority, the less cooperation is considered in society. And barriers such as, family, financial and social barriers affected to the degree of the social cooperation. Also, in his research, the degree of the social cooperation in the formal dimension is very weak among citizens.

\section{Research Methodology}

Present research, is quantified in terms of modality, and measurable in terms of the data collected. In this way, frequency, distribution, and relationships between variables were investigated by selecting and studying the samples selected from the community. The research community consists 600 female students, educating in Ilam universities. Data were collected using collectivism questionnaire and social cooperation questionnaire which were both made and evaluated by the researchers. Questionnaires were answered and completed verbally by referring to the students in each university. Those having open and close questions. After answering, they were collected and entered into the computer after coding. Data were analyzed through descriptive and 


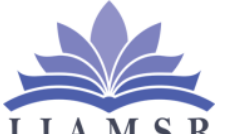

\section{International Journal of Advanced Multidisciplinary Scientific Research (IJAMSR) ISSN:2581-4281}

deductive statistics. Descriptive statistics were used to arrange the tables and percent, accounting; and in deductive partial correlation coefficient was used to answer the questions, and for this purpose, SPSS software has been used. After data collection, individuals were divided into two groups based on the language who speak as the first language, and their frequency and percent were presented. Findings showed that 427 individuals were the speaker of their mother tongue (Kurdish), and 173 individuals were speakers of Farsi language, which were $71 \%$ and $29 \%$ respectively (table 1).

1. Frequency and percent of the students in terms of the first language

\begin{tabular}{|c|c|c|}
\hline The first language & Frequency & percent \\
\hline Kurdish & 427 & $71 \%$ \\
\hline Farsi & 173 & $29 \%$ \\
\hline Total & 600 & $100 \%$ \\
\hline
\end{tabular}

As it has shown in table 1, 71\% Kurd daughters, in Ilam universities, speak in their mother tongue, and $29 \%$ are speakers of Farsi language.

The validity of the questions of questionnaires was assessed using Cronbach Alfa, so that internal validity of the buoys was revealed by accounting this coefficient. Cronbach Alfa is from 0 to 1 , and whatever Alfa is closer to 1 , it means that buoys have higher validity for assessing the subject (table 2).
Table 2. validity results for variables of the research

\begin{tabular}{|c|c|c|c|c|c|c|}
\hline $\begin{array}{c}\text { Independ } \\
\text { ent } \\
\text { variables }\end{array}$ & $\begin{array}{c}\text { dimension } \\
\mathrm{s}\end{array}$ & $\begin{array}{c}\text { Buoy } \\
\mathrm{s}\end{array}$ & $\alpha$ & $\begin{array}{c}\mathrm{KM} \\
\mathrm{O}\end{array}$ & $\begin{array}{c}\text { Explain } \\
\text { ed } \\
\text { varianc } \\
\mathrm{e}\end{array}$ & $\begin{array}{c}\alpha \\
\text { and } \\
\mathrm{KM} \\
\mathrm{O}\end{array}$ \\
\hline $\begin{array}{c}\text { collectivi } \\
\text { sm }\end{array}$ & $\begin{array}{c}\text { Confidenc } \\
\mathrm{e}\end{array}$ & 2 & $\begin{array}{c}0 / 7 \\
\mathrm{n}\end{array}$ & $0 / 85$ & $44 / 81$ & $0 / 90$ \\
\cline { 2 - 7 } & $\begin{array}{c}\text { Fairness } \\
\text { in } \\
\text { assessing }\end{array}$ & 1 & $0 / 8$ & $0 / 78$ & $64 / 53$ & $0 / 90$ \\
\cline { 2 - 7 } & $\begin{array}{c}\text { Tendency } \\
\text { to } \\
\text { convergen } \\
\text { ce }\end{array}$ & 2 & $0 / 8$ & $0 / 90$ & $58 / 40$ & $0 / 90$ \\
\hline $\begin{array}{c}\text { Social } \\
\text { cooperati } \\
\text { on }\end{array}$ & $\begin{array}{c}\text { Cooperati } \\
\text { on moral }\end{array}$ & 5 & $0 / 9$ & $0 / 94$ & $58 / 99$ & $0 / 93$ \\
\cline { 2 - 7 } & $\begin{array}{c}\text { Mental } \\
\text { cooperatio } \\
\mathrm{n}\end{array}$ & 9 & $0 / 8$ & $0 / 80$ & $53 / 64$ & $0 / 93$ \\
\cline { 2 - 7 } & $\begin{array}{c}\text { Objective } \\
\text { cooperatio } \\
\mathrm{n}\end{array}$ & 13 & $0 / 7$ & $0 / 82$ & $55 / 24$ & $0 / 93$ \\
\hline
\end{tabular}

In this research, collectivism assessed in three dimensions (confidence, fairness in assessing, and tendency to convergence), and with 5 buoys. Cooperation moral with 5 buoys, mental cooperation with 9 buoys, and objective cooperation with 13 buoys measured in Likert's 6 options score.

\section{Findings of the research}

\section{Descriptive findings}

In studying the research sample (600 individuals), that were Kurd female students of Public, Azad, Payamnoor, and Gheyre Entefaei universities, of whom 427 individuals spoke in their mother tongue, and 173 ones spoke in another language. After accounting average and minimum-maximum scores, some differences were revealed between daughters speaking their mother tongue and ones speaking another language (table 3 ). 


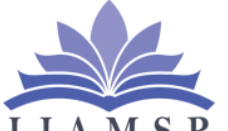

International Journal of Advanced Multidisciplinary Scientific Research (IJAMSR) ISSN:2581-4281

Table 3. table of the collectivism and its dimension state and degree between the students

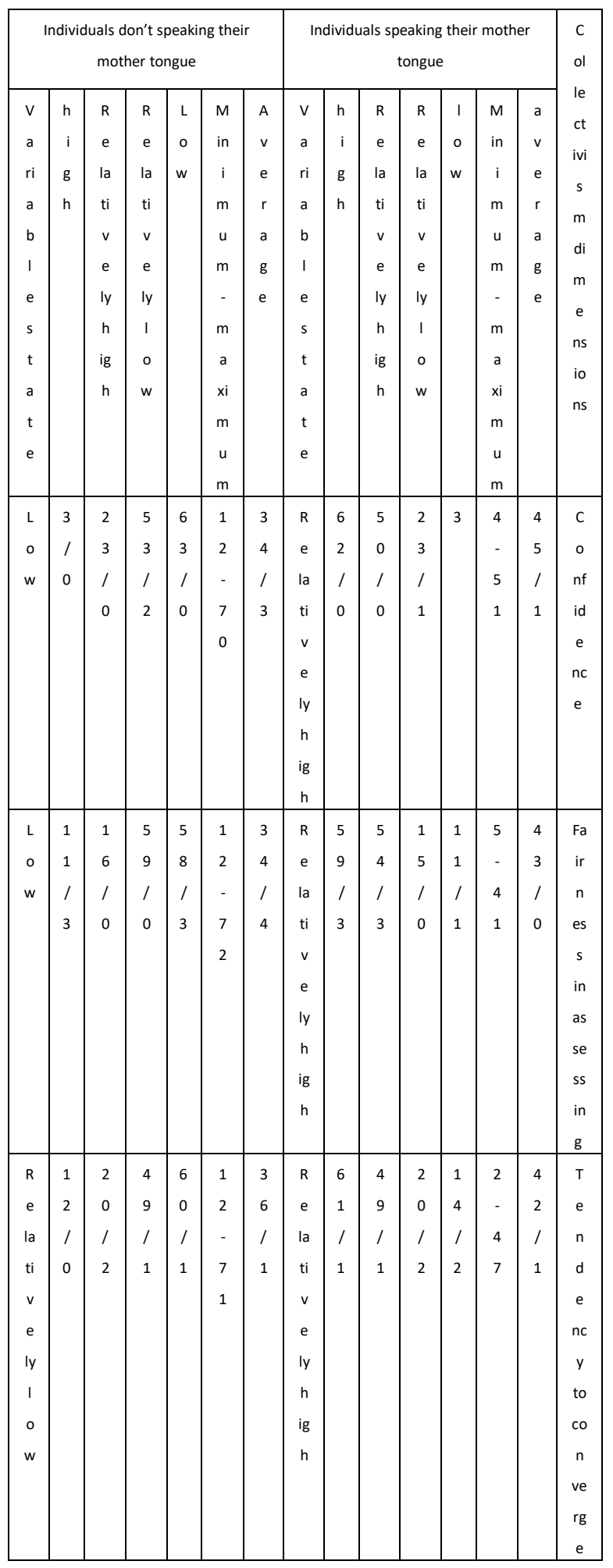

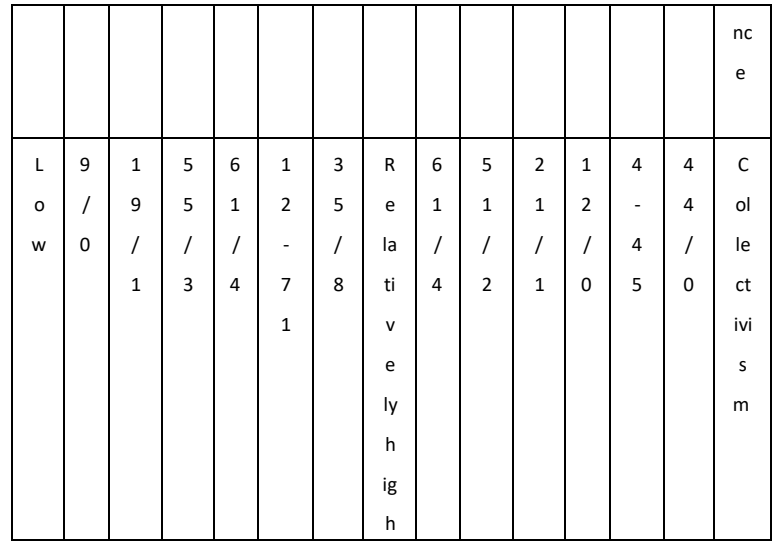

According to the results in the wright side of the table 3, collectivism average is $44 \%$ for the students who speak their mother tongue, with minimum score 4 , and maximum score 45 , so it is relatively high. In the left side of the table 3, collectivism average is $35 / 8 \%$ for the students who don't speak their mother tongue, with minimum score 2, and maximum score 72 , so it is low. As you can see in this table, all dimensions of the variable (confidence, fairness in assessing, and tendency to convergence) have shown such a results.

Table 4. table of the social cooperation and its dimension state and degree between the students

\begin{tabular}{|c|c|c|c|c|c|c|c|c|c|c|c|c|c|c|}
\hline \multicolumn{7}{|c|}{$\begin{array}{l}\text { Individuals who don't speak in their } \\
\text { mother tongue }\end{array}$} & \multicolumn{7}{|c|}{ Individuals who speak in mother tongue } & \multirow{2}{*}{$\begin{array}{l}\text { So } \\
\text { cia } \\
\text { । }\end{array}$} \\
\hline v & $\mathrm{h}$ & $\mathrm{R}$ & $\mathrm{R}$ & । & $M$ & A & V & $\mathrm{h}$ & $R$ & R & 1 & M & A & \\
\hline ar & i & el & el & o & ini & $v$ & ar & $\mathrm{i}$ & el & el & o & ini & v & op \\
\hline ia & $\mathrm{g}$ & at & at & w & $\mathrm{m}$ & er & ia & g & at & at & w & $\mathrm{m}$ & e & er \\
\hline bl & $\mathrm{h}$ & iv & iv & & u & a & bl & $\mathrm{h}$ & iv & iv & & u & ra & ati \\
\hline e & & el & el & & $\mathrm{m}$ & $\mathrm{g}$ & e & & el & el & & $\mathrm{m}$ & $\mathrm{g}$ & on \\
\hline st & & $y$ & $y$ & & - & e & st & & $\mathrm{y}$ & $\mathrm{y}$ & & - & e & di \\
\hline at & & hi & lo & & $\mathrm{m}$ & & at & & hi & lo & & $\mathrm{m}$ & & $\mathrm{m}$ \\
\hline e & & $\mathrm{g}$ & w & & ax & & e & & g & w & & $a x$ & & en \\
\hline & & $\mathrm{h}$ & & & im & & & & $\mathrm{h}$ & & & im & & sio \\
\hline & & & & & $\begin{array}{l}\mathrm{u} \\
\mathrm{m}\end{array}$ & & & & & & & $\begin{array}{l}\mathrm{u} \\
\mathrm{m}\end{array}$ & & ns \\
\hline
\end{tabular}




\section{International Journal of Advanced Multidisciplinary Scientific Research (IJAMSR) ISSN:2581-4281}

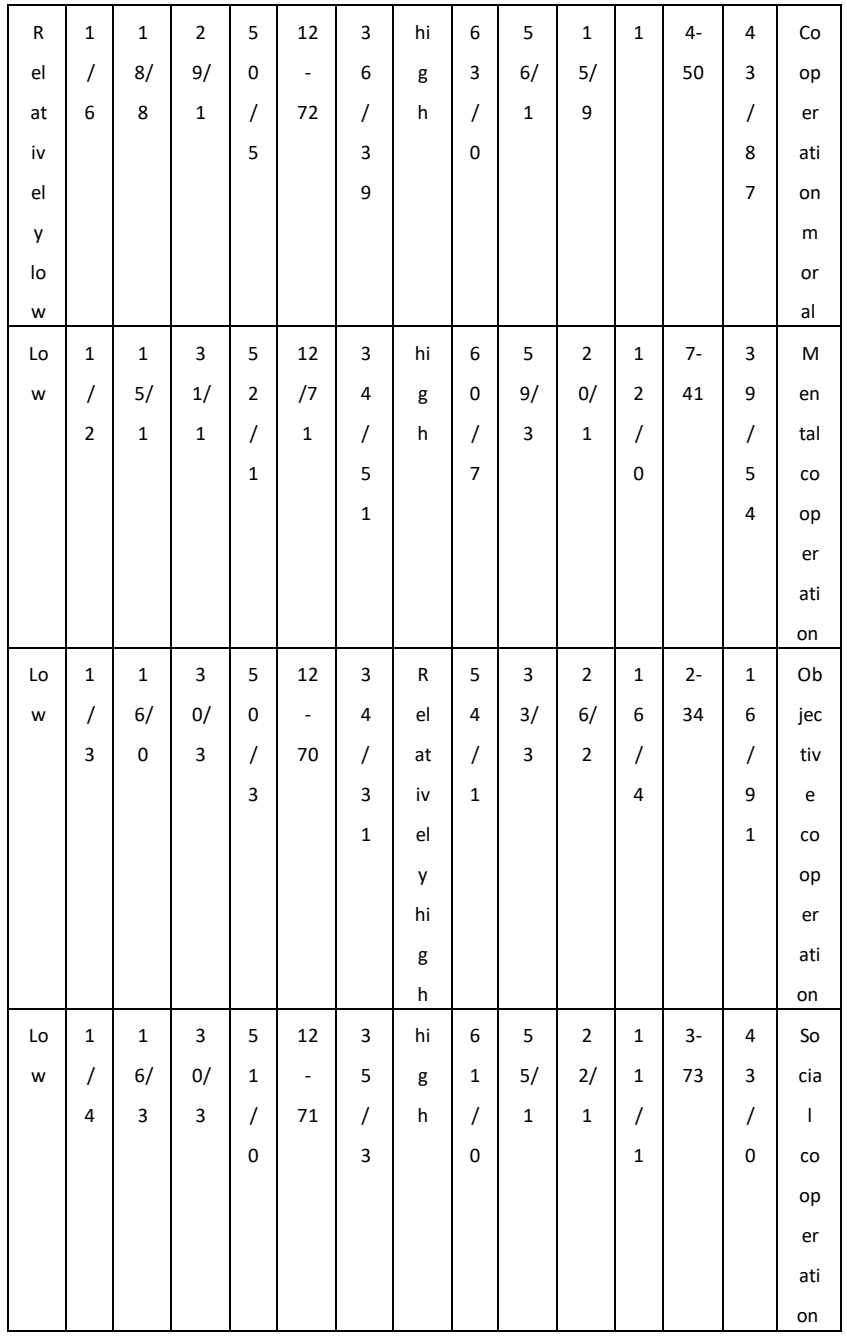

According to the results shown in the wright side of the table 4, social cooperation average is $43 \%$ for the students who speak their mother tongue, with minimum score 3, and maximum score 73 , so it is high. In the left side of the table 4 , social cooperation average is $35 / 3 \%$ for the students who don't speak their mother tongue, with minimum score 12 , and maximum score 71 , so it is low. As you can see in this table, all dimensions of the variable (cooperation moral, mental cooperation, and objective cooperation) have shown such a results. And totally all students who speak in their mother tongue, have more tendency to social cooperation and its dimensions.

\section{Deductive analysis}

In a two variable analysis based on assessing the dependent variables (collectivism and social cooperation), Pierson's coefficient correlation test has been used. Findings showed that there is a meaningful and positive relationship between collectivism and social cooperation. This relation is meaningful in 5\% level. In investigating the relationship between collectivism and the dimensions of social cooperation, confidence had a meaningful relation with all three dimensions of the social cooperation; it means that the higher confidence the higher cooperation, moral, mental cooperation, and objective cooperation, for which correlation coefficients were $0 / 000,0 / 000$, and 0/001 respectively. Results also showed a meaningful relationship between all dimensions of both variables. So whatever dimension of collectivism increase, social cooperation and its dimensions will increase too (table 5).

\section{Table 5. correlation between collectivism and social cooperation and their dimensions}

\begin{tabular}{|c|c|c|c|c|}
\hline Variables & $\begin{array}{c}\text { Objective } \\
\text { cooperatio } \\
\mathrm{n}\end{array}$ & $\begin{array}{c}\text { Mental } \\
\text { cooper } \\
\text { ation }\end{array}$ & $\begin{array}{c}\text { Cooperation } \\
\text { moral }\end{array}$ & $\begin{array}{c}\text { Social } \\
\text { cooperation }\end{array}$ \\
\hline $\begin{array}{c}\text { Collectivi } \\
\text { sm }\end{array}$ & $0 / 267$ & $0 / 221$ & $0 / 108$ & $0 / 212$ \\
$0 / 000$ & $0 / 000$ & $0 / 000$ & $0 / 000$ \\
\hline $\begin{array}{c}\text { Confiden } \\
\text { ce }\end{array}$ & $0 / 299$ & $0 / 385$ & $0 / 230$ & $0 / 178$ \\
Fairness & $0 / 296$ & $0 / 294$ & $0 / 300$ & $0 / 001$ \\
in & $0 / 000$ & $0 / 000$ & $0 / 000$ & $0 / 000$ \\
assessing & & & & $0 / 223$ \\
\hline $\begin{array}{c}\text { Tendency } \\
\text { to }\end{array}$ & $0 / 234$ & $0 / 118$ & $0 / 141$ & $0 / 248$ \\
converge & $0 / 000$ & $0 / 022$ & $0 / 006$ & $0 / 000$ \\
nce & & & & \\
\hline
\end{tabular}




\section{Discus and conclusion}

The findings of the research, analysis answered all questions about this research. As said earlier, the present work is to find answers to three questions: 1) is there a meaningful relationship between mother tongue and collectivism? 2) Is there a meaningful relationship between mother tongue and social cooperation? 3) Is there a meaningful relationship between collectivism and social cooperation? Results represented in table 3 showed that students who speak in their mother tongue, have higher tendency to collectivism and its dimensions. Also, according to the results represented in table 4, that students who speak in their mother tongue, have higher tendency to social cooperation and its dimensions. Finally, in a two variable analysis based on assessing the dependent variables (collectivism and social cooperation), Pierson's coefficient correlation test has been used. Findings showed that there is a meaningful and positive relationship between collectivism and social cooperation. Since, the relationship between mother tongue and personality creation is an undeniable matter, we can know the findings of this research as a result of this fact. When individuals have spoken in a language other than family members' language, an individual personality has been created in them; and they have a low tendency to make communication with others, and it can lead to decrease in the social cooperation too. As Koen believes that a cultural value is in fact one of its confirmed and inherited standards expected from members of the group (Koen, 1991). When an individual saw him/herself in the first group (family) without any value and culture in common, it will be evident that group dependence moral and correlation won't be created in him/her; so he/she will not have commitment to society and social cooperation; and it confirm Bolon's idea in which he knows five skills as effective factors in creating the appropriate relation and communication: listening, expressing one's being skill, cease fire skill, common problems solving skill, and selecting the skill, in all of which language plays a significant role (Bolton, 2002).

\section{Suggestions and problem solving}

Since, research community consists the daughters (future mothers), it seems as a warning danger in our society which is a developing country. Evidently, if our society is to consist individualist persons, no development will be achieved. Training programs are suggested to be provided in institutions and universities in order to aware people, especially the future mothers about this issue. Mothers can train individuals with distinguished and clear personality, interested in communication and cooperation; these characteristics can be generated in a larger group (society) in order to have a developed country in the future. Parents should know that mother tongue acquisition can lead to a better imagine about one's cultural values. 


\section{References:}

1. Bloordi, T\& Bloordi, Z. (2011). "An Investigation of Cooperation Moral in Students and Factors Effecting it (a case study: Azad Islamic Universities in Region 7 of Country)", Iran Sociology Journal, $13^{\text {th }}$ year, N 3, P 57-82.

2. Bolton, Robert (2001). Psychology of the Human Being Communications (Public Skills). Translated by Hamid Reza Sohrabi, Tehran: Roshd Publication.

3. Biro, Allen (2000). Social Sciences Dictionary, translated by Bagher Sarookhani, Tehran: Keyhan.

4. Darbandi, Alireza (2005). An investigation of the Collectivist Behavior and Thought of Tehranian Citizens, M.A Thesis, Sociology filed, Teacher Training University.

5. Riterz, Georg (1994), Sociology Theories in contemporary, translated by Mohsen Salasi, Tehran: Scientific.

6. Toosi, Mohammad Ali (1990). Partnership in Possession and Management, Tehran: Public Management Training Center Publication.

7. Alaei, Bohlool (2005). Relationship of Lingual Nationalism and Collectivism with Farsi Language Application in Institutional environments of a Turkish Region. Research of the Foreign Languages, Publication of Literature and Human Sciences College of Tabriz University, Autumn and Winter 2005.

8. Gaotri, Houin (1999). Cooperation in Development, Translated by Hadi Gheyraei and Davood Tabaei, Tehran: Ravesh.

9. Koen, Broods (1990). An Introduction to Sociolinguistics. Translated by Mohsen Salasi, Tehran: Farhange Moaser, 1990.

10. Nateghpoor, Mohammad Javad (2003). "Development and Social Possession by Emphasizing on the Council Members' Role", the Social Sciences Teaching, Scientific-researching Journal of Investigation of degree of the Social Possession of people... $8^{\text {th }}$ year. Pp 28-32.
11. Yazdan Panah, Leyla (2007). "Barriers of the Social Cooperation of Tehranian Citizens", The Social ease Journal, $7^{\text {th }}$ year, $N 26$.

12. Wenying, J. Handling culture Bumps.ELT Journal, Vol,55/No.4. pp. 382-390. 2001. 